\title{
Post Mortem Reputation, Compensatory Gifts and Equal Bequests*
}

\author{
Michael Lundholm and Henry Ohlsson
}

June 1999

\begin{abstract}
The empirical evidence suggests that parents use inter vivos gifts (i.e., transfers of tangible and financial property) to compensate less well off children whereas post mortem bequests are divided equally among siblings. We study a theoretical model assuming, first, that the amounts given is private information, only known to the donor and the donee, while the amounts bequeathed is public information. Second, we assume that parents care about the reputation that their bequest behavior will leave them after their death. More specifically, this reputation is deteriorating in the difference in amounts inherited. We show that, given these assumptions, the optimal choice of altruistic parents is compensatory gifts and equal bequests.
\end{abstract}

JEL: D10, D31, D63, D64.

Keywords: altruism, bequests, inheritances, gifts, equal division, post mortem reputation, social norm, information.

\footnotetext{
${ }^{*}$ Correspondence to: Michael Lundholm, Department of Economics, Stockholm University, SE-106 91 Stockholm, Sweden, email <mlu@ne.su.se> or Henry Ohlsson, Department of Economics, Uppsala University, P.O. Box 513, SE-751 20 Uppsala, Sweden, email $<$ henry.ohlsson@nek.uu.se>.

We have benefited from comments by an anonymous referee, Nils Gottfries, John Laitner, participants at a workshop in family economics at Stockholm University and seminar participants at Uppsala University.
} 


\section{Introduction}

Empirical studies of intergenerational transfers show that inter vivos gifts tend to be compensatory while post mortem bequests are equally divided among heirs. Dunn and Phillips (1997) find, using US data, that gifts are compensatory; the higher earnings of a child the smaller the received gift. Most empirical studies of estate division find equal division; see Menchik (1988) for the U.S. and Arrondel et al. (1997) for France. ${ }^{1}$ This is a puzzle since established models of intergenerational transfers predict that there is no difference between gift and bequest behaviour. Altruistic parents will make compensatory transfers. ${ }^{2}$

In this paper we study a model of altruistic parents adding two key features: (1) Gifts and bequests differ because gift behaviour is private information, only known to the donor and the donee, whereas bequest behavior is public information, at least known to all heirs through the estate inventory and possibly also even common knowledge, and (2) a social norm of equal division of bequests. Because bequest behaviour is public information parents can affect their post mortem reputation. We assume that while living, parents care about their future reputation and let this affect their transfer behavior. In this model, the utility maximizing transfer behaviour of parents is to make compensatory gifts while dividing bequests equally.

Our assumptions about who knows what are consistent with how tax systems are designed in most industrialized countries. Only very small fractions of total tax revenue are raised by bequest and inheritance taxes even though the estate inventories make estate sizes common knowledge. An explanation often given for this is that increasing bequest and inheritance taxes would make parents shift to inter vivos gifts instead. This argument, however, assumes that it is more difficult to tax gifts than bequests and inheritances. This, in turn, is consistent with gifts being private information.

Laitner (1997,p. 206) writes that social norms may explain why intergenerational transfers are equally divided between siblings. Equal division may curb rent-seeking behaviour of siblings competing over parental resources and also preserves peace within family lines. Wilhelm (1996) assumes that parents suffer from a fixed psychic cost if they deviate from equal division of post mortem bequests, a hypothesis for which he finds some empirical support. Stark (1998), on the other hand, considers a case where a child becomes more

\footnotetext{
${ }^{1}$ Tomes $(1981,1988)$, however, finds that bequests are compensatory.

${ }^{2}$ Cremer and Pestieau (1996), in a model of altrustic parents facing moral hazard and the samaritan's dilemma, generate the prediction that gifts are equal and bequests are compensatory.
} 
deprived if she gets less than her siblings. ${ }^{3}$

In contrast our model (i) allows a trade-off between the reputation effect and the altruistic parent's compensatory ambition and (ii) makes a distinction between intergenerational transfers in the form of inter vivos gifts and post mortem bequests.

\section{$2 \quad$ Altruistic model}

Consider a mother with two unequal daughters, one rich and one poor. We study a standard altruistic model in which the mother cares equally about the daughters. Conditional on the total bequest $b$, we ask how the mother should divide the total bequest. We focus on situations where the mother bequeaths to both daughters; $b_{i}>0 i=r, p$, where $r=$ rich and $p=$ poor. The mother solves

$$
\max _{b_{r}, b_{p}} \ln \left(a_{r}+b_{r}\right)+\ln \left(a_{p}+b_{p}\right)
$$

subject to $b \geq b_{r}+b_{p}$ and where $a_{i}$ is the initial resources of daughter $i=r, p$, such that $a_{r}>a_{p}$. The first order condition for an interior solution implies

$$
b_{p}^{A}-b_{r}^{A}=a_{r}-a_{p} .
$$

The opportunity cost of increasing the bequest to one daughter is the identical reduction in bequest to the other daughter, both measured in marginal utilities of income. The mother will choose to equalise consumption opportunities between daughters. This means that she compensates the poor daughter by setting $b_{p}^{A}>b_{r}^{A}$ such that (2) holds. This solution, which is illustrated as allocation $\alpha$ in Figure 1, is contrary to overwhelming empirical evidence that bequests are equally divided. Note that the solid line with slope 1 is the locus of equal bequest whereas the dotted line with slope 1 is the locus of equal of consumption opportunities.

\section{Post mortem reputation}

We take as our starting point that the bequest behaviour will affect the reputation of the mother after she has died, so that unequal bequests will damage the mother's reputation. This may be the case if there exists a social

\footnotetext{
${ }^{3}$ Stark, however, ignores that the empirical evidence suggests that gifts are compensatory while his model predicts that relative deprivation will make parents tend to provide equal gifts to their daughters.
} 
Figure 1: The altruistic compensatory solution

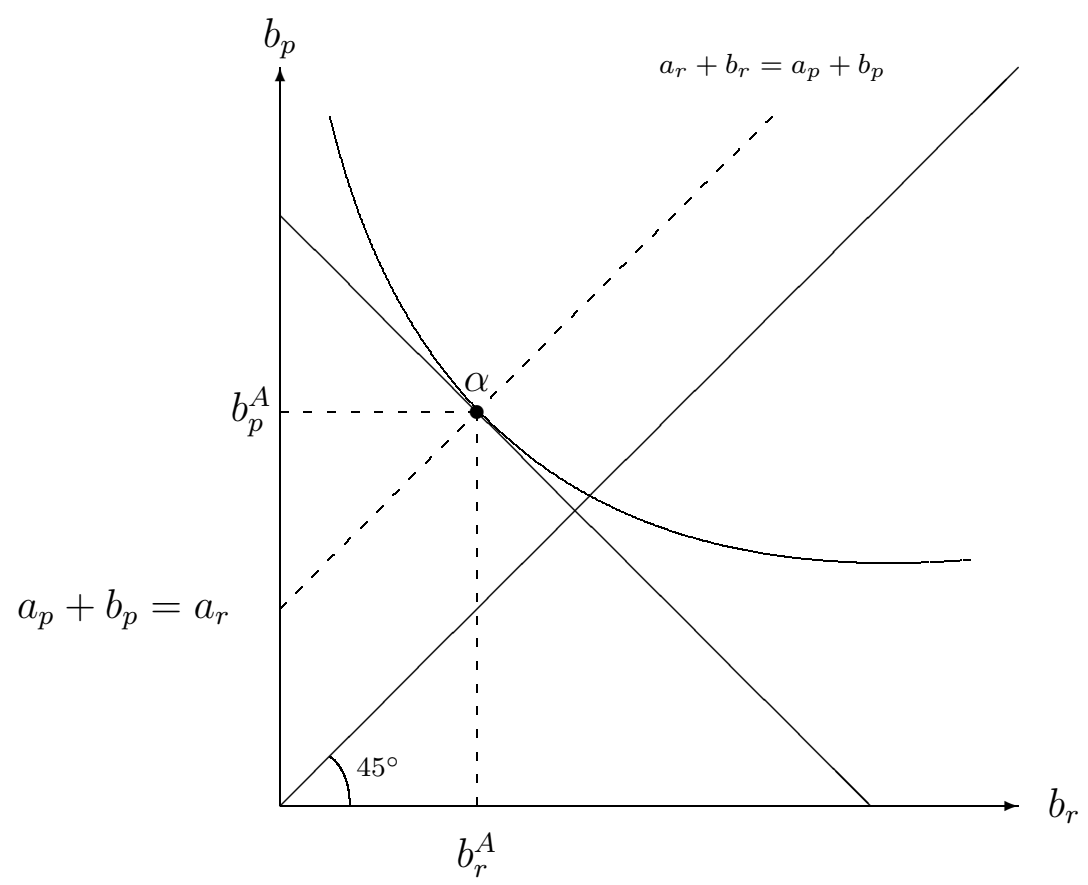

norm saying that all sibblings should be treated equally. Suppose that the mother cares about this reputation in a way such that she solves

$$
\max _{b_{r}, b_{p}} \ln \left(a_{r}+b_{r}\right)+\ln \left(a_{p}+b_{p}\right)-\frac{S}{2}\left(b_{r}-b_{p}\right)^{2}
$$

subject to $b \geq b_{r}+b_{p}$, where $S$ is a positive constant and $\left(b_{r}-b_{p}\right)^{2}$ is the post mortem reputation. An alternative interpretation of the term $-\frac{S}{2}\left(b_{r}-b_{p}\right)^{2}$ is that, as suggested by Laitner (1997), unequal division creates competition among siblings which hurts the mother.

For an interior solution the first order condition implies

$$
\left(b_{p}^{R}-b_{r}^{R}\right) \underbrace{\left[1+2 S\left(a_{r}+b_{r}^{R}\right)\left(a_{p}+b_{p}^{R}\right)\right]}_{>1}=a_{r}-a_{p}
$$

so that $b_{p}^{R}-b_{r}^{R}<a_{r}-a_{p}$. The mother trades off her wish to equalise consumption opportunities between the daughters with her desire for post mortem reputation. She now does not want to equalise the consumption opportunities between daughters. As long as $S$ is finite, $b_{r}=b_{p}$ is never optimal. The optimal solution is illustrated as allocation $\gamma$ in Figure 2. 
Figure 2: The post mortem solution and the not-so compensatory solution

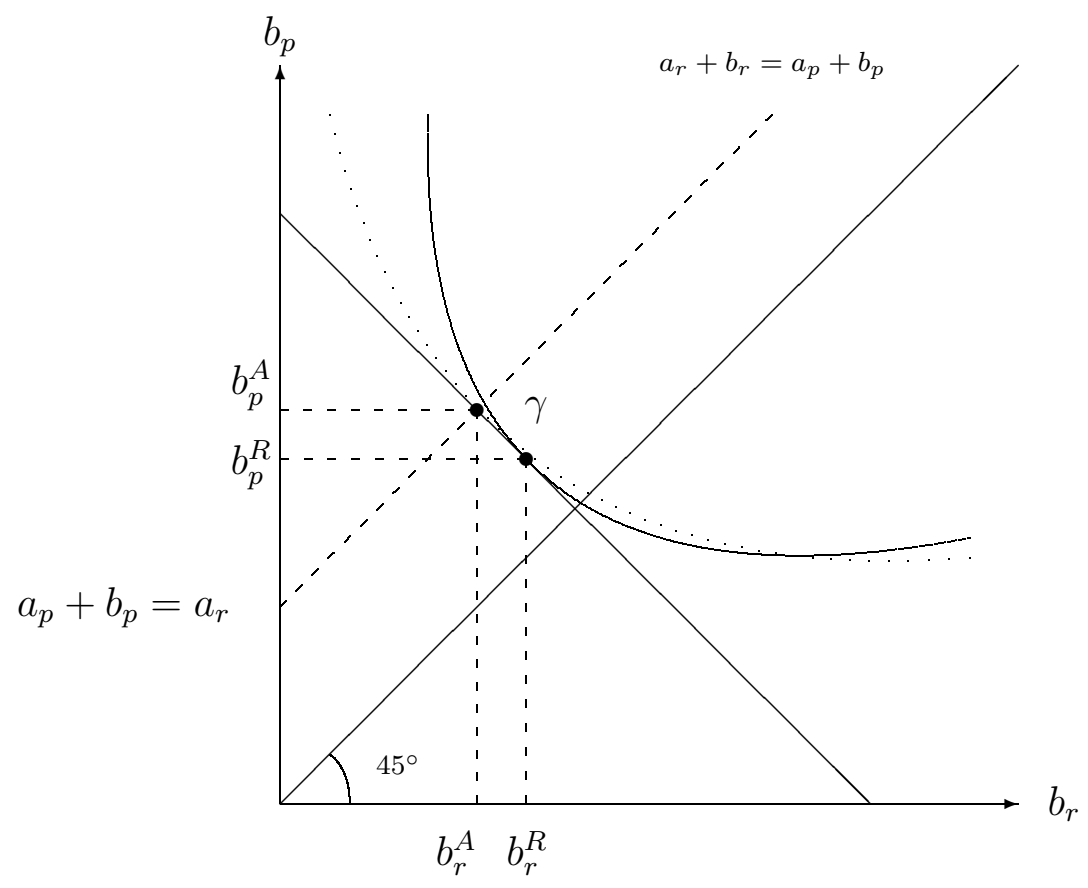

Indifference curves have slope

$$
\left.\frac{d b_{p}}{d b_{r}}\right|_{d U=0}=-\frac{a_{p}+b_{p}}{a_{r}+b_{r}} \cdot \frac{1-S\left(a_{r}+b_{r}\right)\left(b_{r}-b_{p}\right)}{1+S\left(a_{p}+b_{p}\right)\left(b_{r}-b_{p}\right)},
$$

which evaluated at allocation $\alpha$ (where $\left.a_{p}+b_{p}=a_{r}+b_{r}\right)$ is

$$
\left.\frac{d b_{p}}{d b_{r}}\right|_{d U=0} ^{\alpha}=-\frac{1-S\left(a_{r}+b_{r}\right)\left(b_{r}-b_{p}\right)}{1+S\left(a_{r}+b_{r}\right)\left(b_{r}-b_{p}\right)}<-1
$$

since $b_{r}<b_{p}$. Also, at $b_{r}=b_{p}$ the slope is

$$
\left.\frac{d b_{p}}{d b_{r}}\right|_{d U=0} ^{b_{r}=b_{p}}=-\frac{a_{p}+b_{p}}{a_{r}+b_{r}}>-1
$$

given our assumption that $a_{r}>a_{p}$. Now, let $S \rightarrow \infty$. Then, by l'Hôpital's rule

$$
\left.\lim _{S \rightarrow \infty} \frac{d b_{p}}{d b_{r}}\right|_{d U=0}=\lim _{S \rightarrow \infty} \frac{b_{r}-b_{p}}{b_{r}-b_{p}}=1
$$

for all strictly positive bequests $b_{r}, b_{p}$, since by the same rule $\lim _{\left(b_{r}-b_{p}\right) \rightarrow 0} \frac{b_{r}-b_{p}}{b_{r}-b_{p}}=$ 1. Then all weight is given to reputation, so the mother cares only about 
how she divides her bequest and not at all about the welfare of her daughters. The indifference curves are now straight lines with slope 1, where the indifference curve through the origin gives the highest utility. In this extreme case, the model does not any longer provide us with a unique solution; i.e., any $b_{r}=b_{p}=\bar{b}$ such that $\bar{b} \leq b$ solves the mother's problem.

\section{Compensatory gifts and equal bequests}

In this section we add the assumption that the bequest behaviour is public information whereas as gift behaviour is private information. Then bequests but not gifts will affect the reputation of the mother after she has died. Suppose that the mother cares about this reputation in a way such that she solves

$$
\max _{b_{r}, b_{p}, g_{r}, g_{p}} \ln \left(a_{r}+b_{r}+g_{r}\right)+\ln \left(a_{p}+b_{p}+g_{p}\right)-\frac{S}{2}\left(b_{r}-b_{p}\right)^{2}
$$

subject to $b \geq g_{r}+b_{r}+g_{p}+b_{p}$. For an interior solution the first order conditions can be rearranged to

$$
\begin{aligned}
\Delta:=a_{p}+b_{p}^{I}+g_{p}^{I}-\left(a_{r}+b_{r}^{I}+g_{r}^{I}\right) & =0 \quad \text { and } \\
S\left(b_{r}^{I}-b_{p}^{I}\right)\left(a_{p}+b_{p}^{I}+g_{p}^{I}\right)\left(a_{r}+b_{r}^{I}+g_{r}^{I}\right) & =\Delta .
\end{aligned}
$$

Equation (10a) implies that consumption opportunities should be equalised. Given equalisation of consumption, then equation (10b) implies that $b_{r}^{I}=b_{p}^{I}$. Hence

$$
\begin{aligned}
g_{p}^{I}-g_{r}^{I} & =a_{r}-a_{p} \quad \text { and } \\
b_{p}^{I}-b_{r}^{I} & =0,
\end{aligned}
$$

so that gifts are used in a compensating fashion to equalise consumption opportunities and bequests are used to equally divide the mother's remaining wealth among daughters. However, the mother is indifferent between using gifts or bequests to choose her position on the equal consumption locus.

\section{Conclusions}

The empirical evidence suggests that parents use inter vivos gifts (i.e., transfers of tangible and financial property) to compensate less well off children whereas post mortem bequests are divided equally among siblings. We study 
a theoretical model assuming, first, that the amounts given is private information, only known to the donor and the donee, while the amounts inherited is public information. Second, we assume that parents care about the reputation their bequest behavior will leave them after their death. More specifically, this reputation is detoriating in the difference in amounts inherited. We show that, given these assumptions, the optimal choice of altruistic parents is compensatory gifts and equal bequests. In our simple atemporal model, it is not possible to rule out that parents choose to make all transfers as gifts. Additional assumptions, for example uncertain lifetime or precautionary savings, will yield solutions with positive bequests. Still, bequests should be divided equally.

One obvious extention of the present paper is to ask why parents have preferences that make them take into account effects on their post mortem reputation of their behaviour in relation to a social norm? One can note that Coleman (1990,p. 275) argues that externality is a necessary condition for a social norm. Then, one hypothesis is that the norm for equal bequests and the preference parameter $S$ is a response to inefficencies created by e.g., the Samaritan's dilemma. Whether that is the case could be analysed with (indirect) evolutionary game theory (Güth and Yaari 1992). 


\section{References}

L. Arrondel, A. Masson, and P. Pestieau. Bequest and inheritance: Empirical issues and France-U.S. comparison. In G. Erreygers and T. Vandevelde, editors, Is Inheritance Legitimate? Ethical and Economic Aspects of Wealth Transfers, chapter 4, pages 89-125. Springer Verlag, Berlin, 1997.

J. S. Coleman. Foundations of Social Theory. The Belknap Press of Harvard University Press, Cambridge, Massachusetts and London, England, 1990.

H. Cremer and P. Pestieau. Bequests as heir "discipline device". Journal of Population Economics, 9(4):405-414, November 1996.

T. A. Dunn and J. W. Phillips. The timing and division of parental transfers to children. Economics Letters, 54(2):135-137, February 1997.

W. Güth and M. E. Yaari. Explaining reciprocal behavior in simple strategic games: An evolutionary approach. In U. Witt, editor, Explaining Process and Change - Approaches to Evolutionary Economics, pages 23-34. Ann Arbor, Michigan, 1992.

J. Laitner. Intergenerational and interhousehold economic links. In M. R. Rosenzweig and O. Stark, editors, Handbook of Population and Family Economics, volume 1A, chapter 5, pages 189-238. North-Holland, Amsterdam, 1997.

P. L. Menchik. Unequal estate division: Is it altrusim, reverse bequests, or simply noice? In D. Kessler and A. Masson, editors, Modelling the Accumulation and Distribution of Wealth, chapter 4, pages 105-116. Clarendon Press, Oxford, 1988.

O. Stark. Equal bequests and parental altruism: Compatibility or orthogonality. Economics Letters, 60(2):167-171, August 1998.

N. Tomes. The family, inheritance, and the intergenerational transmission of inequality. Journal of Political Economy, 89(5):928-958, October 1981.

N. Tomes. Inheritance and inequality within the family: Equal division among unequals, or do the poor get more? In D. Kessler and A. Masson, editors, Modelling the Accumulation and Distribution of Wealth, chapter 3, pages 79-104. Clarendon Press, Oxford, 1988.

M. O. Wilhelm. Bequest behavior and the effect of heirs' earnings: Testing the altruistic model of bequests. American Economic Review, 86(4):874892, September 1996. 